\title{
Effect of Nano Charcoal Ash Coconut Shell in Bitumen as Alternative Binder
}

\author{
Siti Nur Amiera Jeffry, Ramadhansyah Putra Jaya, Mohd Rosli Hainin, Norhidayah Abdul \\ Hassan, Haryati Yaacob
}

\begin{abstract}
The effect of Nano charcoal ash (NCA) from coconut shell on the physical and chemical properties of bitumen as alternative binder was evaluated in this study. Six different Nano grades of charcoal ash were examined. The charcoal ash ground for the optimum grinding time had a median particle size of 148 nm. NCA dosage of $30 \%$ by weight of binder was used throughout the experiments. Nanoparticle size analysis and $X$-ray fluorescence were performed to determine the size and chemical properties of material. Dynamic shear rheometer, penetration, softening point, and penetration index were used to characterize the physical properties of NCA. Thirty hours of grinding time produced the optimum NCA, which could enhance the binder performance. Test results indicated that adding NCA from coconut shell to bitumen improved the binder stiffness up to $47 \%$ and significantly increased the softening point up to $12 \%$ compared with virgin binder.
\end{abstract}

Index Terms: Nano charcoal Ash; Coconut Shell; Grinding; Penetration; DSR.

\section{INTRODUCTION}

Good quality of pavement should have high structural integrity, which provides a strong, smooth, and safe riding surface for road users. In Malaysia, a common type of distress in asphalt pavement is permanent deformation, which is rutting. Rutting is the type of distress that is easily influenced by climate conditions, traffic volume, and axle loadings because of its viscoelastic behavior. The average temperature in Malaysia is $27{ }^{\circ} \mathrm{C}$, but it can reach up to $35^{\circ} \mathrm{C}$ in the afternoon. At such temperatures the asphalt pavement becomes so hot that it causes the bitumen to soften and deform when pressure from vehicle tires is exerted on it [1]. Rutting occurs when the viscosity of the bitumen is increased and the elasticity is decreased. This phenomenon decreases the efficiency and safety of the asphalt pavement and reduces its service life. This problem can be solved in two ways, namely, to modify the bitumen or to provide a new mix design [2]. The properties of virgin binder are insufficient to resist the distress, which requires considerable research regarding asphalt modification. Various types of materials are used as

Revised Manuscript Received on November 05, 2019.

Siti Nur Amiera Jeffry, Faculty of Engineering, School of Civil Engineering, Universiti Teknologi Malaysia, Johor Bahru, Malaysia Universiti Malaysia Pahang, Gambang, Pahang, Malaysia

Mohd Rosli Hainin, Faculty of Civil Engineering Technology, Universiti Malaysia Pahang, Gambang, Pahang, Malaysia.

Norhidayah Abdul Hassan, Faculty of Engineering, School of Civil Engineering, Universiti Teknologi Malaysia, Johor Bahru, Malaysia

Haryati Yaacob, Faculty of Engineering, School of Civil Engineering, Universiti Teknologi Malaysia, Johor Bahru, Malaysia
Ramadhansyah Putra Jaya, Faculty of Civil Engineering Technology,

bitumen modifiers. The most popular method nowadays is by using agricultural waste materials, such as palm oil fuel ash, rice husk ash, coconut shell, bamboo, rattan, etc. These agricultural wastes are abundantly available in Malaysia which leads to environmental problems. Hence, one of the ways is to reuse them by incorporating them to bitumen modification. Through this alternative, the environment can be protected by reducing the wastes and the construction costs. The incorporation of these waste materials as modifiers is adopted mostly in concrete structures and asphalt pavements. However, no or rare studies are conducted using coconut shell as modifier in bitumen. Nanotechnology has been utilized by researchers for many years, but its usage remains limited [3]. Researchers also have investigated the use of nano-sized particles in composites because the physical and chemical properties of materials can be improved, including bitumen [4,5]. The sizes of nano-sized particles range from $1 \mathrm{~nm}$ to $100 \mathrm{~nm}[3,4,6]$. A small material size typically leads to a high surface area. Accordingly, nanoparticles have higher reactivity than other common-sized particles. Jamshidi et al. [6] reported that nanoparticles can improve both the rheological and engineering properties of bitumen and mixtures. A workshop by the National Science Foundation in 2006 indicated that nanoscience and nanotechnology could lead to improvements in the asphalt pavement technology [7]. Therefore, this study attempts to fill the gap by investigating NCA from coconut shell that is utilized as the main material in the bitumen modification. The effects of NCA on the bitumen subjected to numerous grinding times are evaluated, and the optimum grinding time that can produce the optimum $\mathrm{NCA}$ is determined.

\section{MATERIAL AND METHOD}

\section{A. Raw Materials and Preparation}

The coconut shell from the Peter Haw Enterprise in Melaka, Malaysia was used as the main material in this study. The bitumen used penetration 60/70 in this study was from SHELL. The coconut shell was cleaned and crushed prior to the burning process. The burning process was then conducted by using a furnace at a temperature of $450{ }^{\circ} \mathrm{C}$. Through these processes, the charcoal coconut shell ash (CCSA) was produced. The micro-sized was obtained by sieving to generate a size of $75 \mu \mathrm{m}$, and a ball milling machine was used 
to grind the CCSA to obtain the Nano-size particles. Grinding times of 20,30, 40, 50, and $60 \mathrm{~h}$ were adopted to acquire the optimum Nano-size particles. Comparison of the NCA $(20 \mathrm{~h}$ to $60 \mathrm{~h}$ ground) was made with micro-sized (zero grinding hour) and virgin binder (60/70 PEN). The mixing process of NCA in bitumen was conducted by using a high shear mixer at speeds of $1000 \mathrm{rpm}$ to $1700 \mathrm{rpm}$ for $60 \mathrm{~min}$ to $90 \mathrm{~min}$ at temperatures of $145^{\circ} \mathrm{C}$ to $180{ }^{\circ} \mathrm{C}$. Table 1 shows the mix design of the samples.

\section{Table 1. Designation of Mix Design}

\begin{tabular}{ccc}
\hline Designation & Grinding (hours) & \% Replacement \\
\hline Virgin binder & - & 0 \\
NCA0 & 0 (micro-sized) & \\
NCA1 & 20 & \\
NCA2 & 30 & 30 \\
NCA3 & 40 & \\
NCA4 & 50 & \\
NCA5 & 60 \\
\hline
\end{tabular}

\section{B. X-Ray Fluorescence (XRF) Test}

$\mathrm{XRF}$ test is an analytical technique used to conduct elemental analysis that involves bulk chemical analysis of major elements in geological materials. The test can be performed on liquids, solids, or loose powders. This instrument works through the interactions of samples with electron beam and X-rays [8]. In this research, XRF was conducted to determine the chemical elements of the NCA.

\section{Nanoparticle Size Analysis Test}

Nanoparticle size analysis test was used to determine the size of the NCA for several grinding times. Fig. 1 shows the instrument that measured the particles and the molecules sizes ranging from $20 \mathrm{~nm}$ to $2000 \mu \mathrm{m}$ using dynamic light scattering. Zeta potential was also equipped for suspension stability measurements, electrophoretic mobility, and molecular weight accessories.

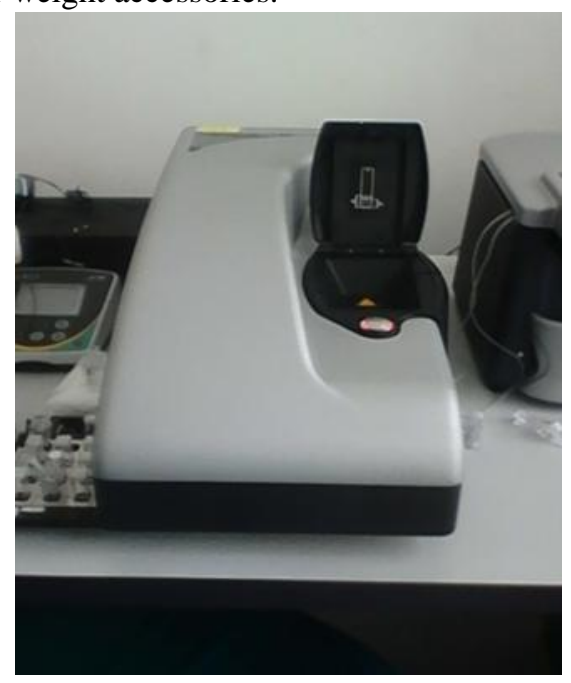

Fig.1. Nanoparticle size analyzer

\section{Penetration Test}

The consistency of the bitumen was measured by the penetration test according to the standard ASTM D5/D5M-13 [9]. This is the simplest test to obtain the penetration value of the bitumen. A low value of penetration indicates the hardness of the bitumen. The bitumen was heated and poured into a penetration cup prior to testing. The sample was then placed into a water bath for $1 \mathrm{~h}$ at $25{ }^{\circ} \mathrm{C}$ after it was cooled. The penetration equipment was used to perform the test with the applied total load of $100 \mathrm{~g}$ for $5 \mathrm{~s}$ at a temperature of $25^{\circ} \mathrm{C}$.

\section{E. Softening Point Test}

Considering the viscoelastic behavior, the consistency of the bitumen must be determined to establish the uniformity of shipments. Bitumen does not have a definite temperature to soft. Therefore, determining the softening point of bitumen is important for result comparison. The softening point test was conducted according to ASTM D36/D36M [10]. The bitumen was heated and poured into two rings and cooled for $30 \mathrm{~min}$. The two rings and two ball centering guide were placed on the ring holder in a liquid bath. Subsequently, $3.5 \mathrm{~g}$ of steel balls were placed on each sample and heated. The temperature that made the bitumen touched the base plate was taken, and the mean temperature of the two samples was calculated.

\section{F. Dynamic Shear Rheometer (DSR)}

The use of DSR is to measure the rheological properties of bitumen. This test was conducted in accordance with ASTM D175-15 [11]. The viscoelastic behavior of bitumen can be determined by the complex shear modulus, $G^{*}$, and phase angle, $\delta$, at intermediate to high temperatures. $\mathrm{G}^{*}$ and $\delta$ values depend on the test temperature and frequency of loading. In DSR, the test was conducted at a temperature of $6{ }^{\circ} \mathrm{C}$ increment, which was from $46{ }^{\circ} \mathrm{C}$ to $82{ }^{\circ} \mathrm{C}$. As for the frequency, the test was conducted at frequencies of $0.01 \mathrm{~Hz}$ to $100 \mathrm{~Hz}$ at temperatures of $46{ }^{\circ} \mathrm{C}$ to $70{ }^{\circ} \mathrm{C}$ with $6{ }^{\circ} \mathrm{C}$ increments. The rutting performance of the asphalt pavements can also be analyzed from $\mathrm{G}^{*} / \sin \delta$. For the unaged bitumen, 1 $\mathrm{mm}$ thick plate and $25 \mathrm{~mm}$ diameter top plate were used. The bitumen sample was sandwiched between two $1 \mathrm{~mm}$ thick plates. Stress was applied on top of the sample by the $25 \mathrm{~mm}$ diameter of the top plate, which oscillated at $1.59 \mathrm{~Hz}$, to measure the maximum stress, maximum strain, and time lag of stress and strain.

\section{RESULTS AND ANALYSIS}

\section{A. XRF}

Table 2 shows the main chemical compositions of the NCA, which were obtained from the XRF. The carbon content of $93.9 \%$ was the highest element that was needed to be used in bitumen. NCA also consisted of hard elements, which were silica, aluminum, and ferum [12] with $1.21 \%, 0.319 \%$, and $0.267 \%$, respectively. Other metal elements were potassium, sodium, calcium, and magnesium. The presence of chlorine also showed the occurrences of oxidizing agent, which was $0.28 \%$, but not enough to influence much on bitumen. Most bitumen from numerous crude oils contains $82 \%$ to $88 \%$ of carbon [13].

Published By:
Blue Eyes Intelligence Engineering Exploring Innovation and En
\& Sciences Publication


Thus, the incorporation of the NCA into bitumen was compatible because of the high carbon composition of the material. The chemical compositions of materials usually vary depending on the material source and the occurrence of contaminations caused by the way of material handling.

Table 2. Chemical Compositions of NCA

\begin{tabular}{cc}
\hline Chemical element & Percentage $(\%)$ \\
\hline C-carbon & 93.9 \\
K-potassium & 1.47 \\
Si-silica & 1.21 \\
Na-sodium & 1.16 \\
Ca-calcium & 0.847 \\
Al-aluminium & 0.319 \\
Mg-magnesium & 0.292 \\
Cl-chlorine & 0.28 \\
Fe-ferum/iron & 0.267 \\
\hline
\end{tabular}

\section{B. Nanoparticle Size Analysis}

Based on Table 3, the size of the NCA was decreased to $148 \mathrm{~nm}$ after $30 \mathrm{~h}$ of grinding and then kept on increasing after 40,50 , and $60 \mathrm{~h}$ of grinding. The results did not follow the expected trend, that is, a long grinding time leads to a small size of the materials. This phenomenon can be explained through the mechanism of the ball milling. The ball milling was used to reduce the material size. The ball mill consists of a cylinder bowl, two steel rods, and steel balls of numerous sizes. The cylinder bowl rotates in one direction, whereas the supporting disc rotates another way around [14,15] as shown in Fig. 2. This rotation leads to the rotation and pounding of the CCSA with the steel rods and balls [15]. This kinetic process makes the particle break to smaller sizes because of the striking and impact applied by the steel rods and balls to the powder mixture. Factors that lead to this condition are decrease of rates of particle breakage, agglomeration and exceed the optimum grinding time. A research conducted by Nikmatin et al. [16] proved that the finest particle sizes of materials were not produced by the longest grinding time. They were achieved by optimum grinding time to produce optimum sizes of materials instead. In other words, the grinding process to produce desired fine particle sizes could be achieved by performing the grinding up to a certain period of time. The rates of particle breakage also differed for different types of materials. Determining the optimum grinding time is therefore important to obtain required sizes of materials to be incorporated into bitumen for further investigations. However, all sizes still do not achieve the range of $1 \mathrm{~nm}$ to $100 \mathrm{~nm}$. Hence, the methods to prepare the sample before grinding need to be modified. In this experiment, $30 \mathrm{~h}$ can be expected to be the optimum grinding time to achieve the ideal nano-size particles with modification of the material preparation.

Table 3. Particle Size of NCA

\begin{tabular}{ccc}
\hline Designation & $\begin{array}{c}\text { Grinding time } \\
\text { (hours) }\end{array}$ & Size \\
\hline NCA0 & 0 & $75 \mu \mathrm{m}$ \\
NCA1 & 20 & $343 \mathrm{~nm}$ \\
NCA2 & 30 & $148 \mathrm{~nm}$ \\
NCA3 & 40 & $661 \mathrm{~nm}$ \\
\hline
\end{tabular}

\begin{tabular}{lll}
\hline NCA4 & 50 & $1374 \mathrm{~nm}$ \\
NCA5 & 60 & $1987 \mathrm{~nm}$ \\
\hline
\end{tabular}

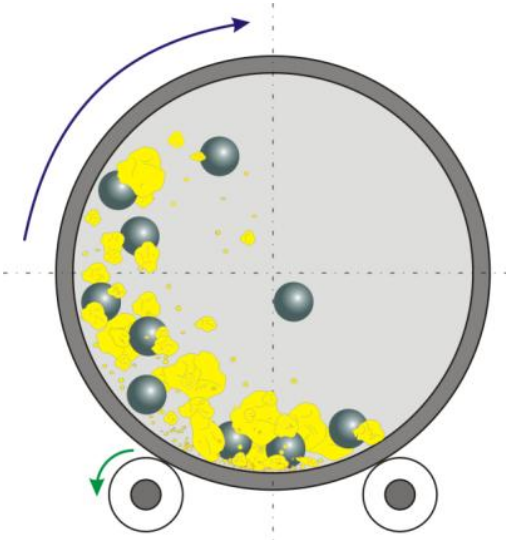

Fig.2. Ball mill [15]

\section{Cost}

Based on the Table 4, NCA grinding consumed $37.26 \mathrm{kWh}$ of energy costing RM 13.60 each day, according to electricity tariff $\mathrm{C} 1$ (commercial tariff) [17]. Power consumption of the ball mill was calculated based on Eq. (1) [18].

Ball mill power $(\mathrm{HP})=\mathrm{W} \times \mathrm{C} \times \sin$ a $\times 2 \pi \times \mathrm{N} / 33000$

Where (Based on Fig.3): W-weight of charge (lb); C-distance of Centre of gravity (ft); a- dynamic angle of repose of the charge and $\mathrm{N}$-mill speed (rpm).

Grinding for 20, 30, 40, 50 and 60 hours led to total energy consumption of $41.4,62.1,82.8,103.5$ and $124.2 \mathrm{kWh}$ respectively. The total cost for 20 hours of grinding was RM 15.10 and took two days to be completed. Meanwhile, 60 hours of grinding has a total cost of RM 45.30 with four days needed to complete grinding. Hence, if the grinding needs to be carried out for 30 days, energy consumption and cost will be $1117.8 \mathrm{kWh}$ and RM 408 per month respectively. This approximate calculation shows that grinding materials by using the ball mill for hours, involves high energy consumption and is expensive. However, this grinding method was performed based on the laboratory scale. The ball mill with $60 \mathrm{rpm}$ speed was used to produce the nano-sized materials. The energy consumption and cost are dependent on the types of equipment that are available for the research (method) in addition to other factors. Presumably, the production of materials by the industry may require low energy consumption and expense compared to the laboratory scale.

Table 4. Energy consumption and grinding cost of NCA

\begin{tabular}{l|c|c|c|c|c}
\hline Grinding time (h) & 20 & 30 & 40 & 50 & 60 \\
\hline $\begin{array}{l}\text { Energy } \\
\text { consumption per } \\
\text { day (kWh/day) }\end{array}$ & 37.26 & 37.26 & $\begin{array}{c}37.2 \\
6\end{array}$ & 37.26 & 37.26 \\
\hline &
\end{tabular}


Effect of Nano Charcoal Ash Coconut Shell in Bitumen as Alternative Binder

\begin{tabular}{|c|c|c|c|c|c|}
\hline \multirow{3}{*}{$\begin{array}{lr}\text { Next } & \text { energy } \\
\text { consumption }(\mathrm{kWh})\end{array}$} & 4.14 & 24.84 & $\begin{array}{c}37.2 \\
6\end{array}$ & 37.26 & \multirow{2}{*}{$\begin{array}{l}37.26 \\
37.26\end{array}$} \\
\hline & & & 8.28 & 28.98 & \\
\hline & & & & & 12.42 \\
\hline $\begin{array}{ll}\text { Total } & \text { energy } \\
\text { consumption } & (\mathrm{kWh})\end{array}$ & 41.4 & 62.1 & 82.8 & 103.5 & 124.2 \\
\hline $\begin{array}{lll}\text { Energy cost* per } \\
\text { day (RM/day) }\end{array}$ & 13.6 & 13.6 & 13.6 & 13.6 & 13.6 \\
\hline $\begin{array}{l}\text { Total cost for each } \\
\text { grinding time }(\mathrm{RM})\end{array}$ & 15.1 & 22.7 & 30.2 & 37.8 & 45.3 \\
\hline
\end{tabular}

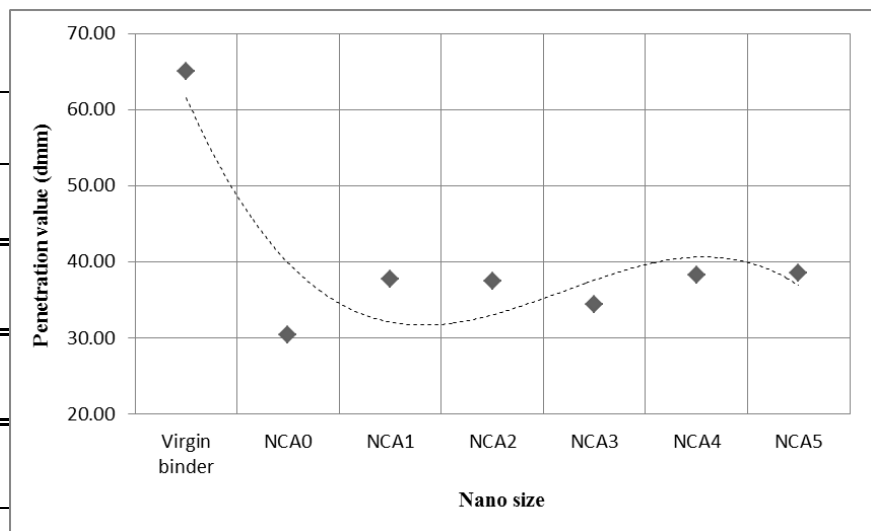

$*$ Cost $=$ RM0.365/kWh > Tariff C1: For all kWh- Medium Voltage General Commercial Tariff

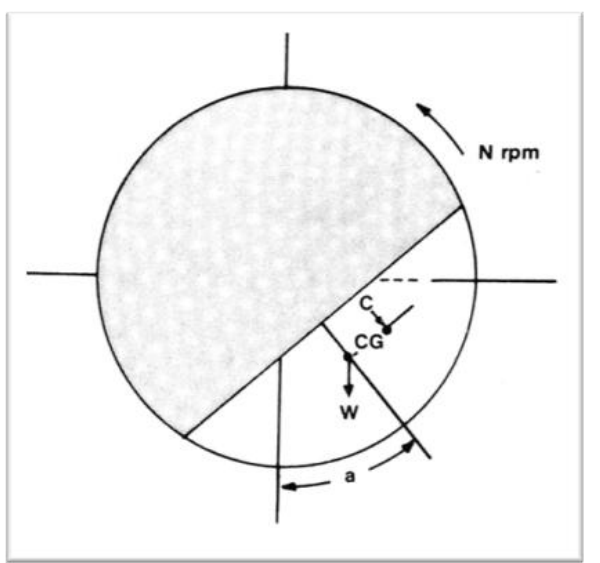

Fig. 3. Section of ball mill in operation [18]

\section{Penetration}

Fig. 4 shows the penetration values of the modified bitumen samples that were compared with the virgin binder as a control sample. Based on the graph, the incorporation of NCA into the bitumen gave lower penetration values than the virgin binder. The NCA0 showed the lowest penetration value compared with the NCA1 to NCA5, which was $30.40 \mathrm{dmm}$. In this test, the NCA3 showed the lowest penetration value after the NCA0, which was $34.40 \mathrm{dmm}$. The NCA3 was $13 \%$ higher and $47 \%$ lower than the NCA0 and the virgin binder, respectively. Therefore, $30 \%$ replacement of NCA could improve about half of the stiffness of the bitumen. The internal strength of the bitumen improved as well. Although the NCA0 showed the highest improvement, being too stiff is not good as well because it will cause another problem to the asphalt pavements. A low penetration value typically leads to high stiffness of the bitumen. However, being too stiff will make the bitumen less elastic and reduce the flexibility of the asphalt pavements. This can lead to cracking because of the asphalt pavement cannot accommodate traffic loading [1]. Hubbard and Gollomb [9] reported that when penetration occurred between 20 and $30 \mathrm{dmm}$, cracking could happen. When the penetration was above $30 \mathrm{dmm}$, the bitumen would have high resistance to cracking added with proper mix design and compact [20].
Fig. 4. Penetration values of bitumen modified by NCA

\section{E. Softening Point}

Based on the results shown in Fig. 5, the NCA3 had the highest softening point value, which was $50.3{ }^{\circ} \mathrm{C}$ and was $12 \%$ higher than the virgin binder. A high softening point indicated that the binder was less susceptible to temperature. Even though the penetration value for the NCA0 was better than the NCA3, in the softening point test, the value was lower than those for the NCA3 and NCA4 for approximately $2 \%$ and $0.4 \%$, respectively. The penetration value and softening point of the bitumen were not compatible. Penetration index (PI) was therefore calculated to determine the compatibility of the bitumen.

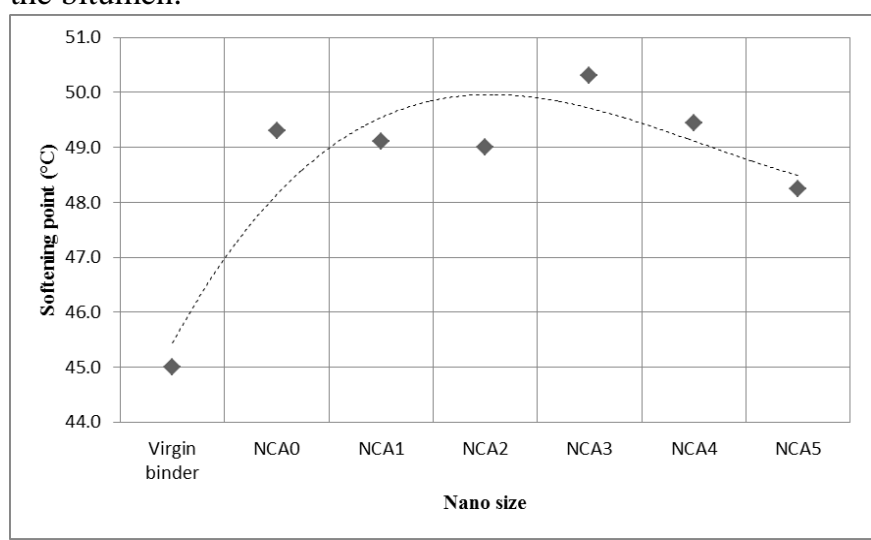

Fig. 5. Softening point of bitumen modified by NCA

\section{F. Penetration Index}

PI is used to determine the consistency of bitumen with temperature, in which the consistency of the softening point is expressed in terms of penetration by linear extrapolation of the logarithm of penetration versus temperature, as shown in Eq (2) [13].

$$
\mathrm{PI}=\frac{1951.4-500 \log P-20 S P}{50 \log P-S P-120.14}
$$

The suitable PI for road construction is between -1 and +1 [20]. A low value of PI, which is approaching the negative, means the sample has high -temperature susceptibility for both rutting and cracking [20,21]. A high value of PI, which is approaching the positive, indicates high resistance to low and high temperatures [21]. Based on the results in Table 5, the PI 
for the virgin binder and NCA modified bitumen did not lie within the range. However, the less negative value showed that the sample was improved [21]. The lowest PI was obtained by the NCA0, which was -2.4 . By contrast, the highest PI was gained by the Virgin binder, NCA3, and NCA4 with the same value of -1.9 . The NCA0 approached a more negative value, which meant that the sample had high influence by the temperature compared with the NCA1 to NCA5. According to Brown et al. (Brown et al. 2009), the bitumens that had PI lower than -2 were typically susceptible to low temperatures, thereby leading to brittleness and transverse cracking during cold weather. Hadavand [21] and Raman et al. [22] reported that if the PI value was -1 and downward, the bitumen was categorized as temperature -susceptible bitumen (tars).

Table 5. PI value

\begin{tabular}{cc}
\hline Designation & Penetration Index (PI) \\
\hline Virgin binder & -1.9 \\
NCA0 & -2.4 \\
NCA1 & -2.0 \\
NCA2 & -2.0 \\
NCA3 & -1.9 \\
NCA4 & -1.9 \\
NCA5 & -2.2 \\
\hline
\end{tabular}

\section{G. DSR}

The results revealed (Fig. 6) that the NCA modified bitumens had a higher $\mathrm{G}^{*} / \sin \delta$ at a temperature range of $46^{\circ} \mathrm{C}$ to $82{ }^{\circ} \mathrm{C}$ than the virgin binder. $\mathrm{G}^{*} / \sin \delta$ is a parameter used to indicate the rutting performance of asphalt pavements [6]. The most significant point was that the NCA modified bitumens reached until $76{ }^{\circ} \mathrm{C}$ to $82{ }^{\circ} \mathrm{C}$ before failure compared with the virgin binder that failed at a temperature of $70{ }^{\circ} \mathrm{C}$. The NCA0 showed a higher $\mathrm{G}^{*} / \sin \delta$ at $46^{\circ} \mathrm{C}$, which was $63.56 \mathrm{kPa}$. The minimum $\mathrm{G}^{*} / \sin \delta$ at $46{ }^{\circ} \mathrm{C}$ was presented by the NCA3 with a value of $32.72 \mathrm{kPa}$. The second highest $\mathrm{G}^{*} / \sin \delta$ at $46{ }^{\circ} \mathrm{C}$ was generated by the NCA1, which was $56.55 \mathrm{kPa}$, followed by the NCA2 with $50.67 \mathrm{kPa}$. Even though at $46{ }^{\circ} \mathrm{C}$, the percentage differences between NCA2 and NCA0 and between NCA2 and NCA1 were $20 \%$ and $10 \%$, respectively. It showed that NCA2 had lower temperature susceptibility than the $\mathrm{NCA} 0$ and $\mathrm{NCA} 1$; this sample reached the temperature of $82{ }^{\circ} \mathrm{C}$ prior to failure at $0.53 \mathrm{kPa}$. Therefore, the NCA2 had the highest resistance to rutting.

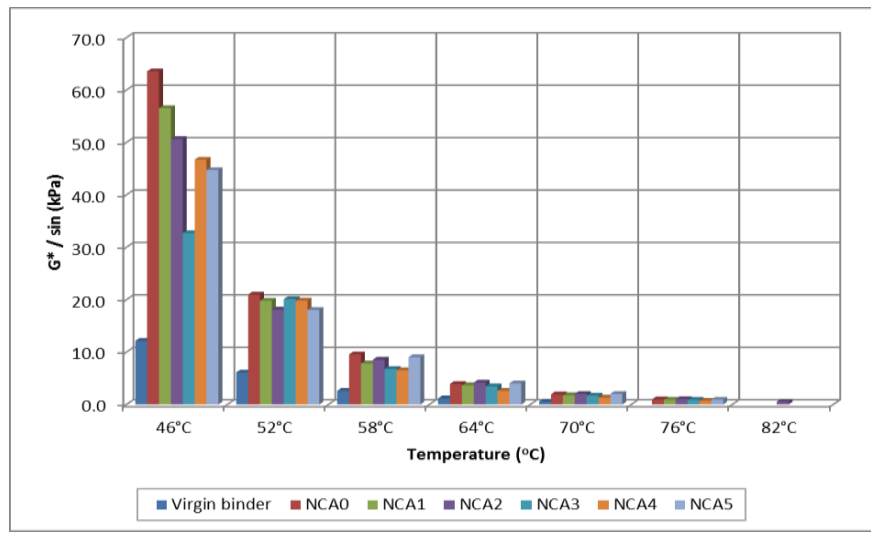

Fig. 6. Effects of NCA modified bitumen on $\mathrm{G} * / \sin \delta$ at different temperatures

\section{H. Rate of Change}

The rate of change for one unit percent of material replacement could be determined by using the gradient of the non-dimensional superpave rutting factor [6]. It was simplified for the purpose of this research only, as shown in Eq. (2).

$$
\text { Rate of change }(\%)=\frac{\frac{(G * / \sin \delta) m-(G * / \sin \delta) c}{(G * / \sin \delta) c}}{\% m-\% c}
$$

Where $\mathrm{m}$ is the modified sample, and $\mathrm{c}$ is the control sample.

Based on Table 6, the replacement of NCA in bitumen increased the relative $\mathrm{G} * / \sin \delta$. The $\mathrm{NCA} 0$ had the highest rate of change at $46{ }^{\circ} \mathrm{C}$, which was $14.10 \%$. Therefore, the replacement of $1 \%$ of NCA increased the relative $\mathrm{G}^{*} / \sin \delta$ by $14.10 \%$ at $46{ }^{\circ} \mathrm{C}$. Subsequently, the replacement of $1 \%$ of NCA in bitumen increased the NCA1, NCA2, NCA3, NCA4, and NCA5 by $12.18 \%, 10.57 \%, 5.64 \%, 9.48 \%$, and $8.94 \%$, respectively. These values showed that the relative $\mathrm{G}^{*} / \sin \delta$ was improved by that much amount with $1 \%$ replacement in virgin binders at $46{ }^{\circ} \mathrm{C}$. The effects of increasing temperature on the rate of change in the relative $\mathrm{G}^{*} / \sin \delta$ could also be determined [6]. The rate of change for the NCA2 at $46{ }^{\circ} \mathrm{C}$ was $10.57 \%$, which was $3.53 \%$ lower than that for the NCA0. At $76{ }^{\circ} \mathrm{C}$, the rates of change for the NCA0 and NCA2 were $8.32 \%$ and $8.95 \%$, respectively. The NCA2 achieved a rate of change of approximately $0.63 \%$ higher than the NCA0, which led it to increase until $76{ }^{\circ} \mathrm{C}$ and then to reduce at $82{ }^{\circ} \mathrm{C}$ before failure. Therefore, the critical temperature for the NCA2 was $76{ }^{\circ} \mathrm{C}$. Based on this analysis, the NCA2 had the highest rutting resistance up to $76^{\circ} \mathrm{C}$ compared with other bitumens. The NCA2 could improve the rutting resistance by providing both values of $\mathrm{G}^{*}$ and $\delta$ to come out with viscoelastic asphalt pavements [20]. 
Table 6. Rate of change to replace $1 \%$ of NCA in bitumen

\begin{tabular}{cccccccc}
\hline & \multicolumn{7}{c}{ Temperatures } \\
\cline { 2 - 8 } Designation & $46^{\circ} \mathrm{C}$ & $52^{\circ} \mathrm{C}$ & $58^{\circ} \mathrm{C}$ & $64^{\circ} \mathrm{C}$ & $70^{\circ} \mathrm{C}$ & $76^{\circ} \mathrm{C}$ & $82^{\circ} \mathrm{C}$ \\
\hline NCA0 & 14.10 & 8.07 & 8.83 & 7.72 & 8.13 & 8.32 & \\
NCA1 & 12.18 & 7.44 & 6.63 & 6.97 & 7.08 & 7.64 & \\
NCA2 & 10.57 & 6.52 & 7.54 & 8.44 & 8.66 & 8.95 & 8.49 \\
NCA3 & 5.64 & 7.60 & 5.30 & 6.45 & 6.73 & 7.55 & \\
NCA4 & 9.48 & 7.45 & 4.99 & 4.04 & 4.54 & 5.21 & \\
NCA5 & 8.94 & 6.48 & 8.14 & 8.01 & 8.71 & 7.74 & \\
\hline
\end{tabular}

\section{DISCUSSIONS}

The effects of NCA produced by various grinding times were investigated through physical and rheological tests. The results from the penetration test showed that the NCA0 gave the lowest penetration value, followed by the NCA3. As for the softening point test, the NCA3 gave the highest value, followed by the NCA4 and NCA0. However, based on the rutting performance test to validate the consistency of the bitumen, the NCA2 showed high resistance to rutting compared with the virgin binder and modified bitumen. Although the NCA3 showed higher penetration and softening point values than the NCA2, the later improved the resistance to temperature susceptibility higher than other modified samples. The PI for the NCA2 was -2.0 , which meant it was not easily prone to brittleness. This sample achieved viscoelastic states, which was not too hard or too soft. Bitumen needs to be stiffened and elastic at the same time to recover the amount of surface loading by traffic and to reduce rutting. This analysis indicated that the grinding time of the materials did affect the $\mathrm{G}^{*} / \mathrm{sin} \delta$ of the bitumen. The grinding time of the materials determined the size of the materials obtained, and different sizes did affect the properties of the bitumen. This finding was proven by the nanoparticle size analysis, which showed that the NCA2 produced the smallest size, which was $148 \mathrm{~nm}$. A small size of particle provided a large surface area, which could improve the material properties effectively. The effects of grinding time were also reported by Nikmatin et al. [16]. They adopted three variations of grinding time using a hammer mill, which were 15,30 , and $45 \mathrm{~min} ; 30 \mathrm{~min}$ was selected as the grinding time that could give the desired nano-sized of materials. Jamshidi et al. [6] indicated that the type and amount of nano-materials influenced the $\mathrm{G}^{*} / \mathrm{sin} \delta$ as well. Thus, from this preliminary study, $30 \mathrm{~h}$ ground of CCSA (NCA2) improved the physical and rheological properties of bitumen.

\section{ConClusions}

The following conclusions could be drawn based on the objectives of this preliminary test:

a) The optimum grinding time that showed the highest performance of bitumen was $30 \mathrm{~h}$, which produced the optimum size of $148 \mathrm{~nm}$.

b) The incorporation of NCA increased the stiffness of the bitumen up to $47 \%$ and increased the softening point value by approximately $12 \%$ higher than the virgin binder.

c) The PI values for the modified bitumen were not within the specified range, but the values did not exceed -2 , except for the NCA0 and NCA5.

d) As for the DSR, the resistance to the rutting performance was increased for all the modified bitumens.

\section{ACKNOWLEDGMENT}

The support provided by the Malaysian Ministry of Higher Education and Universiti Malaysia Pahang in the form of a research grant (RDU/UMP) vote number RDU1803160 for this study is highly appreciated.

\section{REFERENCES}

1. Astana, D. A. (2010). "The Effect of Epoxy Bitumen Modification On Hot Mix Asphalt Properties and Rut Resistance." Universiti Teknologi Malaysia.

2. Hainin, M. R., Abdulridha, A. A., Yaacob, H., Haron, Z., and Yusoff, N. I. (2013). "Fatigue life of Malaysia hot mix asphalt mixtures.” Malaysia J. Civ. Eng., 25(1), 94-105.

3. Yang, J., and Tighe, S. (2013). "A Review of Advances of Nanotechnology in Asphalt Mixtures." Procedia - Soc. Behav. Sci., 96 (2013), 1269-1276.

4. Rajak, M. A. A., Majid, Z. A., and Ismail, M. (2015). "Morphological Characteristics of Hardened Cement Pastes Incorporating Nano-palm Oil Fuel Ash." Procedia Manuf., 2(2015), 512-518.

5. Shafabakhsh, G. H., and Ani, O. J. (2015). "Experimental investigation of effect of nano $\mathrm{TiO} 2 / \mathrm{SiO} 2$ modified bitumen on the rutting and fatique performance of asphalt mixtures containing steel slag aggregates." Constr. Build. Mater., 98, $692-702$. 
6. Jamshidi, A., Mohd Hasan, M. R., Yao, H., You, Z., and Hamzah, M. O. (2015). "Characterization of the rate of change of rheological properties of nano-modified asphalt.” Constr. Build. Mater., 98, 437-446.

7. Fang, C., Yu, R., Liu, S., and Li, Y. (2013). "Nanomaterials applied in asphalt modification: A review." J. Mater. Sci. Technol., 29(7), 589-594.

8. Geochemical instrumentation and analysis. (2015). "Integrating research and education." <http://serc.carleton.edu/research_education/geochemsheets/tec hniques/XRF.html>.

9. ASTM D5. (2013). "Standard Test Method for Penetration of Bituminous Materials." American Society for Testing and Materials, West Conshohocken, PA, United States.

10. ASTM D36. (2000). "Standard Test Method for Softening Point of Bitumen (Ring-and-Ball Apparatus)." American Society for Testing and Materials, West Conshohocken, PA, United States.

11. ASTM D7175. (2015). "Standard Test Method for Determining the Rheological Properties of Asphalt Binder Using a Dynamic Shear Rheometer." American Society for Testing and Materials, West Conshohocken, PA, United States.

12. Madakson, P. B., Yawas, D. S., and Apasi, a. (2012). "Characterization of Coconut Shell Ash for Potential Utilization in Metal Matrix Composites for Automotive Applications ." Int. J. Eng. Sci. Technol., 4(03), 1190-1198.

13. Read, J., and Whiteoak, D. (2003). The Shell bitumen handbook. Thomas Telford Publishing, London.

14. Cao, W. (2012). "Synthesis of nanomaterials by high energy ball milling." Skyspring nanomaterials, inc., <http://www.ssnano.com>.

15. Generalic, E. (2015). "Ball mill. Croatian-English Chemistry Dictionary \& Glossary." <http://glossary.periodni.com>.

16. Nikmatin, S., Syafiuddin, A., Kueh, A. B. H., and Purwanto, Y. A. (2015). "Effects of nanoparticle filler on thermo-physical properties of rattan powder-filled polypropylene composites." J. Teknol., 77(16), 181-187.

17. TNB. (2016). "Pricing \& Tariffs." Tenaga Nasional Berhad, <https://www.tnb.com.my/residential/pricing-tariffs/>.

18. 911 Metallurgist. (2015). "Ball Mill Design/Power Calculation." <https://www.911 metallurgist.com/blog/ball-mill-design-powerexample-calculation>.

19. Hubbard, P. and Gollomb, H. (1973). "The hardening of asphalt with relation to development of cracks in asphalt pavements." Proceedings AAPT, 9.

20. Brown, E. R., Kandhal, P. S., Roberts, F. L., Kim, Y. R., Lee, D.-Y., and Kennedy, T. W. (2009). Hot mix asphalt materials, mixture design and construction. NAPA research and education foundation, United States of America.

21. Hadavand, B. S. (2010). "Bitumen modification with polysulphide polymer prepared from heavy end waste." Iran. Polym. J., 19(5), 363-373.

22. Raman, N. A. A., Hainin, M. R., Hassan, N. A., Ani, F. N., M.Warid, M. N., Idham, M. K., and Mamat, R. (2015). "Effect of bio-oil from empty fruit bunch on penetration index of asphalt binder." Jurnal teknologi, 77(23), 13-16. 